\title{
The effect of contextual diversity on eye movements in Chinese sentence reading
}

\author{
Qingrong Chen ${ }^{1,2} \cdot$ Xin Huang ${ }^{1} \cdot$ Le Bai ${ }^{1} \cdot$ Xiaodong $\mathrm{Xu}^{3}$. \\ Yiming Yang ${ }^{4} \cdot$ Michael K. Tanenhaus ${ }^{1,2}$
}

Published online: 18 July 2016

(C) Psychonomic Society, Inc. 2016

\begin{abstract}
Recent studies have demonstrated that when contextual diversity is controlled token word frequency has minimal effects on visual word recognition. With the exception of a single experiment by Plummer, Perea, \& Rayner (2014, Journal of Experimental Psychology: Learning, Memory, and Cognition, 40, 275-283), those studies have examined words in isolation. The current studies address two potential limitations of the Plummer et al. experiment. First, because Plummer et al. used different sentence frames for words in different conditions, the effects might be due to uncontrolled differences on the sentences. Second, the absence of a frequency effect might be attributed to comparing higher and lower frequency words within a limited range. Three eyetracking experiments examined effects of contextual diversity and frequency on Mandarin Chinese, a logographic language, for words embedded in the normal sentences. In Experiment 1 , yoked words were rotated through the same sentence frame.
\end{abstract}

Qingrong Chen

jscqr80@sina.com

$\triangle$ Xin Huang

huangxincoral@foxmail.com

Yiming Yang

yangym@jsnu.edu.cn

$\triangle$ Michael K. Tanenhaus

mtanenha@ur.rochester.edu

1 School of Psychology, Nanjing Normal University, Nanjing, China

2 Department of Brain and Cognitive Sciences, University of Rochester, Rochester, NY 14627, USA

3 School of Foreign Languages and Cultures, Nanjing Normal University, Nanjing, China

4 School of Linguistic Sciences, Jiangsu Normal University, Jiangsu, China
Experiments $2 \mathrm{a}$ and $2 \mathrm{~b}$ used a design similar to Plummer et al., which allows use of a larger sample of words to compare results between experiments with a smaller and larger difference in $\log$ frequency ( 0.41 and 1.06 , respectively). In all three experiments, first-pass and later eye movement measures were significantly shorter for targets with higher contextual diversity than for targets with lower contextual diversity, with no effects of frequency.

Keywords Reading · Contextual diversity · Word frequency · Eye movements

\section{Introduction}

Word frequency is one of the most studied variables in the visual word recognition and reading literatures; as frequency increases, processing time decreases. Of particular interest here are the effects of word frequency on eye movements in reading. Frequency affects both early (first-pass) and later eye movement measures (e.g. Inhoff \& Rayner, 1986; Rayner \& Duffy, 1986; Williams \& Morris, 2004; see Plummer, Perea, \& Rayner, 2014 for recent discussion and review).

Recently, striking evidence has emerged that effects previously attributed to token frequency might be better accounted for by metrics that take into account the range of contexts in which a word occurs. For example, Adelman and colleagues (2006) operationalized a measure, contextual diversity, (CD) the proportion of texts in a corpus in which a word occurs. $C D$ is typically correlated with frequency; high typically occur in a wide variety of contexts. However, when Adelman et al. (2006) used databases to manipulate frequency, while controlling for $\mathrm{CD}$, and vice versa, $\mathrm{CD}$ accounted for nearly all of the variance in naming and lexical decision times. The same pattern is observed with young developing readers (Hills, 
Maouene, Riordan, \& Smith, 2010; Perea, Soares, \& Comesaña, 2013) and has been replicated with related measures (Adelman \& Brown, 2008; Hoffman, Lambon Ralph, \& Rogers, 2013; Hoffman, Rogers, \& Lambon Ralph, 2011; Johns, Gruenenfelder, Pisoni, \& Jones, 2012; Jones, Johns, \& Recchia, 2012; Steyvers \& Malmberg, 2003; Yap, Tan, Pexman, \& Hargreaves, 2011).

CD and related measures capture an important aspect of the relationship between contexts and the likelihood of encountering a word form as well as a given sense of a word. If frequency effects can be reduced to CD effects, it would have important consequences for how we conceptualize and manipulate context in studies of visual and spoken word recognition. Typically, context is manipulated locally, i.e., with a sentence or two. However, an equally important aspect of context might be a more general notion, such as topic, which might affect the likelihood of occurrence of otherwise unrelated words. For example, "balk" occurs relatively infrequently but it is much more likely to occur in a description of a baseball game. Moreover, the relative frequency of syntactic structures that a word occurs in varies with word sense, which can be strongly influenced by context. In a baseball context, the types of syntactic structures, that the verb "walked" appears in, and their relative frequencies, differ from nonbaseball contexts. We return to these issues in the general discussion.

Most studies manipulating $\mathrm{CD}$ and frequency measure responses to words in isolation. An exception is Plummer et al. (2014), who monitored eye movements in sentences, which more closely approximates normal reading. Reading times were longer for words with lower CD than for words with higher CD. When CD was controlled, there were no reliable effects of frequency.

There are two important limitations of Plummer et al.'s experiment. Plummer et al. created separate sentences for words from three groups: (a) Control words; (b) Lower frequency words (LWF) words with the same CD as the Control words; and (c) Higher CD words matched in frequency with the Control words. It is challenging to construct plausible sentences in which target words from different conditions are rotated through the same sentence frames, which likely influenced Plummer et al.'s design. However, a replication with a rotated design would make it less likely that either the effects of CD or the absence of frequency effects could be attributed to uncontrolled differences in sentence frames. Experiment 1 uses a design in which yoked triples of LWF, Control and HCD words are rotated through the same sentence frame.

Few low frequency words have high $C D$ values, thus restricting the range of frequencies that can be compared. Moreover in Plummer et al.s' results, and in the results we report there are small, but consistent, numerical differences between the Control words and the LWF words that would be consistent with a small frequency effect. In Plummer et al., for example, six of the seven measures show this pattern. In Experiment 2 we manipulated the size of the frequency differences between the Control and the LWF words. Reading times increase as a linear function of log frequency. Therefore, any differences due to frequency should increase as the log difference in frequency between the conditions increases.

The current studies used Mandarin Chinese, which has a logographic orthography, with frequency and CD computed from a corpus of words and characters used in films (Cai \& Brysbaert, 2010). Word frequency has similar effects on eye movements in Chinese and in English (e.g., Li \& Pollatsek, 2011; Liversedge, Zang, Zhang, Bai, Yan, \& Drieghe, 2014), which makes it reasonable to compare results across the two languages.

\section{Experiment 1 - Frequency and contextual diversity: Words rotated through sentence frames}

In all of the experiments reported here, we compared three groups of words: A control group with higher frequency words and lower CD words; a lower frequency (LWF) group with a similar $\mathrm{CD}$ as the Control group but lower frequency; and a higher-CD (HCD) group but higher frequency. A higher CD, lower frequency condition was not included because we could not identify sufficient low frequency words with higher $\mathrm{CD}$. The contrasts of primary interest are the LWF group with the Control group, which would reveal any effects of frequency with CD controlled and the HCD group with the Control group, which would reveal any effects of $\mathrm{CD}$ with frequency controlled.

\section{Method}

\section{Participants}

Participants were 30 native Mandarin Chinese speakers with normal or corrected-to-normal vision. Participants gave informed consent and were paid $20 \mathrm{RMB}$.

\section{Materials}

Target words for all experiments were chosen from SUBTLEX-CH-WF (Cai \& Brysbaert, 2010), which provides values of word frequency based on the log10 transformed number of occurrences from 33 million words and CD based on the $\log 10$ transformed number of films in which the word appears in a 6,243 film corpus. We chose this corpus because Cai and Brysbaert (2010) found that 
frequencies based on this database explain more of the variance in word and character reading than frequencies based on written texts - the Language Corpus System of Modern Chinese, Center from Chinese Linguistics Character Frequency, and the Lancaster Corpus of Modern Chinese.

Twenty-seven word triples were selected. LWF words have a similar CD as the Control group $(t(52)=1.62, p=0.11)$ with a lower word frequency, $t(52)=12.67, p<0.001$. HCD words have similar frequencies as the Control group $(t(52)=-0.79, p$ $=0.43$ ) but with a higher $C D$ value, $t(52)=-13.26, p<0.001$. Target words are two-character compound nouns matched in number of stokes $(t<1.34, p \mathrm{~s}>0.18)$, radicals $(t \mathrm{~s}<1.24, p \mathrm{~s}>$ $0.22)$, orthographic neighborhood size $(t \mathrm{~s}<0.64, p \mathrm{~s}>0.53)$, and semantic diversity ( $t \mathrm{~s}<0.77, p \mathrm{~s}>0.44$ ). The values for each measure in each condition are presented in the Appendix Table 8

We created 27 sentence frames and rotated target words from each triple through the same frame across three lists (see examples 1a-1c). Each list contained nine sentences from each condition, with one version of each sentence.

1a. 爷爷收藏的陨石是他挚爱的珍宝。

The meteorite my grandpa collected is his treasure.

$1 b$. 爷爷收藏的牛角是他挚爱的珍宝。

The ox horn my grandpa collected is his treasure.

$1 \mathrm{c}$. 爷爷收藏的古董是他挚爱的珍宝。

The antique my grandpa collected is his treasure.

\section{Control norms}

For the three studies we report, separate groups of 20-25 participants rated the plausibility and the difficulty of the experimental sentences on a 7-point scale. Word predictability was assessed using a cloze completion task in which the target word was replaced by a blank. For Experiment 1, there were no significant differences between conditions $(t \mathrm{~s}<0.82, p \mathrm{~s}>0.41)$ in difficulty or plausibility. The target word appeared in $2.22 \%$ of completions, with no significant difference across conditions $(t \mathrm{~s}<0.22, p \mathrm{~s}>0.83)$.

\section{Apparatus}

Eye movements were monitored using a SensoMotoric Instruments (Teltow/Berlin, Germany) iView Hi-Speed system, sampling at $1,250 \mathrm{~Hz}$ (tracking resolution $<0.01^{\circ}$ ). Viewing was binocular but data were collected only from the right eye. Sentences were presented on a 17-in. CRT monitor. Each character subtended $1.05^{\circ}$ of visual angle at a viewing distance of $70 \mathrm{~cm}$. Stimulus presentation and response collection used the E-Prime software package (Psychology Software Tools, Pittsburgh, PA, USA).

\section{Procedure}

Trials began with presentation of a fixation point $(+)$ left aligned with the first character. The order of the 27 experimental sentences and 27 filler sentences was randomized for each participant. Participants were instructed to read each sentence silently at their normal rate and then answer a yes/ no question. The experiment began with eight practice sentences.

\section{Results and discussion}

All participants responded correctly to at least $90 \%$ of the questions. Reading times for critical words were analyzed as target regions. We excluded $5.42 \%$ percentages of trials because of track losses, blinks, and fixations shorter than $80 \mathrm{~ms}$, longer than $800 \mathrm{~ms}$, three standard deviations above or below mean fixation time (Chen \& Huang, 2012). Means for each dependent measure are presented in Table 1.

We computed three "first-pass" measures considered to primarily reflect early processes and three measures considered to reflect later processes (Rayner, 1998, 2009). First-pass measures were first-fixation duration, gaze duration, and skipping rate. Later measures were go-past time, regression rate, and total fixation time. Planned comparisons used linear mixed-effects models for fixation durations and mixed logit models for skipping using the lme4 package (Bates, Maechler, \& Bolker, 2012) in R (R Development Core Team, 2014). The regression model included fixed effects (e.g., log-transformed word frequency and log-transformed $\mathrm{CD}$ ) and the maximal random effects structure with by-participants and by-items random intercepts and slopes (Barr, Levy, Scheepers, \& Tily, 2013; Jaeger, 2008). We report $t$-values for linear mixedeffects models, $z$-values for mixed logit models, and corresponding $p$-values (see Table 2). For $t$-values, the lmerTest package was implemented, for mixed effects models we

Table 1 Eye movement measures on target words in each group

\begin{tabular}{llll}
\hline Measure & Control group & LWF group & HCD group \\
\hline FFD (ms) & $312(5.56)$ & $314(5.40)$ & $289(5.22)$ \\
GD (ms) & $383(5.49)$ & $375(6.38)$ & $335(8.39)$ \\
Skipping & $0.09(0.02)$ & $0.08(0.02)$ & $0.10(0.02)$ \\
Go-past (ms) & $482(5.56)$ & $491(5.40)$ & $409(5.14)$ \\
Reg. in & $0.13(0.02)$ & $0.16(0.02)$ & $0.11(0.02)$ \\
TTime (ms) & $517(10.52)$ & $542(13.11)$ & $458(12.73)$ \\
\hline
\end{tabular}

Note. Participant means with standard errors in parentheses for Firstfixation duration (FFD), Gaze duration (GD), Skipping rate (Skipping), Go-past time (Go-past), Regression rate (Reg. in), and Total fixation time (TTime) by condition in target region 
Table 2 Regression coefficients and test statistics from linear mixed-effects and logistic mixed-effects models for eye movement measures on the target

\begin{tabular}{|c|c|c|c|c|c|c|c|}
\hline & & FFD & GD & Skipping & Reg.in & Go-past & TTime \\
\hline \multirow{4}{*}{ Control group vs. LWF group } & Est. $\beta$ & 2.19 & -7.75 & -0.03 & 0.03 & 9.19 & 25.47 \\
\hline & $t$-value & 0.28 & -0.97 & & 0.73 & 1.15 & 1.13 \\
\hline & $z$-value & & & -0.05 & & & \\
\hline & $p$-value & 0.785 & 0.337 & 0.963 & 0.479 & 0.257 & 0.271 \\
\hline \multirow[t]{4}{*}{ Control group vs. HCD group } & Est. $\beta$ & -22.74 & -46.31 & 0.48 & -0.02 & -73.49 & -58.23 \\
\hline & $t$-value & -2.83 & -3.63 & & -0.51 & -9.18 & -3.01 \\
\hline & $z$-value & & & 0.96 & & & \\
\hline & $p$-value & 0.009 & 0.001 & 0.339 & 0.617 & $<0.0001$ & 0.006 \\
\hline
\end{tabular}

estimated $p$ values using the Satterthwaite approximation for degrees of freedom (Kuznetsova, Christensen, \& Brockhoff, 2014).

\section{Effects of word frequency (control group vs. LWF group)}

Fixations to low and high frequency words did not differ in either the first-pass measures, all $t \mathrm{~s}<1, p \mathrm{~s}>0.33, \beta \mathrm{s}<2.20$, or measures reflecting later processing, all $t \mathrm{~s}<1.16, p \mathrm{~s}>0.25, \beta \mathrm{s}$ $<25.50$. Differences in skipping rate were not reliable, $z<$ $0.10, p>0.90$.

\section{Effects of contextual diversity (control group vs. HCD group)}

For first-pass measures, HCD target words had shorter firstfixation durations $(\beta=-22.74)$ and gaze durations $(\beta=-46.31)$ than words with lower $\mathrm{CD}, t \mathrm{~s}>-2.80, p \mathrm{~s}<0.01$. The effect of $\mathrm{CD}$ in skipping rate was not significant, $z<1, p>0.33$.

For later measures, go-past time $(\beta=-73.49)$ and total fixation time $(\beta=-58.23)$ were shorter for words with higher $\mathrm{CD}$ than for words with lower $\mathrm{CD}, t \mathrm{~s}>-3.01, p \mathrm{~s}$ $<0.007$. The regression rates did not differ significantly $(\beta=-0.02)$.

In sum, $\mathrm{CD}$ affected eye-movement measures reflecting both early and later processes with no effects of word frequency when $\mathrm{CD}$ was controlled. Because we embedded the words from the different conditions in the same sentence frames, the results cannot be plausibly attributed to differences in sentence frames.

Finally, we note that the first-fixation durations are relatively long. They are, however, within the range of frequently occurring fixations for reading Mandarin (see Li, Bicknell, Liu, Wei, \& Rayner, 2014 for a distribution of fixation times). We return to this issue when we present the results for Experiment 2a, which has shorter fixation durations, and Experiment 2b, where the fixation durations are similar to this Experiment.

\section{Experiment 2 - Comparison between studies with different-sized frequency ranges}

Differences between the LWF and the Control condition did not approach significance in Experiment 1. However, the direction of the effects for four of the six measures is consistent with small increases in processing difficulty for the LWF words. For example, the (mean) Total Reading Time for the LWF words and the Control words is $542 \mathrm{~ms}$ and $517 \mathrm{~ms}$, respectively. There was a similar pattern in Plummer et al. (2014) for six of seven measures. In Experiment 2 we compare results between two comparably powered experiments (Experiments $2 \mathrm{a}$ and $2 \mathrm{~b}$ ) in which the frequency difference between the LWF words and the Control words differs in size. If there are underlying frequency

Table 3 Experimental conditions and exemplar sentences

\begin{tabular}{|c|c|c|c|}
\hline Condition & Example & Difficulty & Plausibility \\
\hline \multicolumn{4}{|l|}{ Exp. 2a } \\
\hline Control & $\begin{array}{l}\text { 小姑娘画的飞船看来非常像。 } \\
\text { The craft that little girl painted } \\
\text { looks realistic. }\end{array}$ & $\begin{array}{l}1.41 \\
(0.05)\end{array}$ & $\begin{array}{l}5.22 \\
(0.14)\end{array}$ \\
\hline LWF & $\begin{array}{l}\text { 爸爸买的珍珠竟然是一件假货。 } \\
\text { The pearl that dad bought is } \\
\text { actually a fake. }\end{array}$ & $\begin{array}{l}1.43 \\
(0.07)\end{array}$ & $\begin{array}{l}5.28 \\
(0.17)\end{array}$ \\
\hline HCD & $\begin{array}{l}\text { 工程师想到的借口有点儿虚假。 } \\
\text { The excuse that engineer } \\
\text { came up with is somewhat } \\
\text { false. }\end{array}$ & $\begin{array}{l}1.47 \\
(0.05)\end{array}$ & $\begin{array}{l}5.23 \\
(0.14)\end{array}$ \\
\hline \multicolumn{4}{|l|}{ Exp. 2b } \\
\hline Control & $\begin{array}{l}\text { 表姐认为这种风尚值得赞扬宣传。 } \\
\text { Cousin thinks that this fashion } \\
\text { is praiseworthy. }\end{array}$ & $\begin{array}{l}1.42 \\
(0.05)\end{array}$ & $\begin{array}{l}5.38 \\
(0.13)\end{array}$ \\
\hline LWF & $\begin{array}{c}\text { 游客发现火光吓跑了一些动物。 } \\
\text { The tourists find that the fire } \\
\text { scares the animals away. }\end{array}$ & $\begin{array}{l}1.36 \\
(0.05)\end{array}$ & $\begin{array}{l}5.47 \\
(0.14)\end{array}$ \\
\hline $\mathrm{HCD}$ & $\begin{array}{l}\text { 老师觉得这个例子非常形象生动。 } \\
\text { The teacher thinks that the } \\
\text { example is very vivid. }\end{array}$ & $\begin{array}{l}1.34 \\
(0.04)\end{array}$ & $\begin{array}{l}5.41 \\
(0.13)\end{array}$ \\
\hline
\end{tabular}

Note: The target words are in bold. Means and standard errors are computed across each condition. 
Table 4 Eye movement measures on target words in Experiment 2a

\begin{tabular}{llll}
\hline Measure & Control group & LWF group & HCD group \\
\hline FFD (ms) & $231(3.46)$ & $236(3.17)$ & $216(3.06)$ \\
GD (ms) & $298(6.15)$ & $309(6.80)$ & $268(4.60)$ \\
Skipping & $0.10(0.01)$ & $0.09(0.01)$ & $0.13(0.01)$ \\
Go-past (ms) & $467(9.92)$ & $477(8.49)$ & $396(5.92)$ \\
Reg. in & $0.19(0.02)$ & $0.25(0.02)$ & $0.15(0.01)$ \\
TTime (ms) & $437(9.81)$ & $463(10.48)$ & $366(5.92)$ \\
\hline
\end{tabular}

Note: All standard errors are provided in parentheses

effects, differences between the LWF words and the Control words should be larger in Experiment $2 b$.

In Experiment 2a mean log frequencies for the LWF and Control words are 2.36 and 2.77, respectively. In Experiment $2 \mathrm{~b}$, the log frequency differences are substantially larger: 1.30 and 2.36, respectively. Each word was placed in its own sentence frame, allowing us to use a larger set of items than in Experiment 1.

\section{Experiment 2}

\section{Method}

Experiments $2 \mathrm{a}$ and $2 \mathrm{~b}$ used the same apparatus and procedure as Experiment 1.

\section{Participants}

Participants were 90 native Mandarin Chinese speakers with normal or corrected-to-normal vision, 45 each for Experiment $2 \mathrm{a}$ and $2 \mathrm{~b}$. Participants gave informed consent and were paid 20 RMB.

For each experiment, we selected 48 words with 16 words for each condition (see Table 3). Words in the LWF group have a similar CD to the control condition
( $t \mathrm{~s}<1.60, p \mathrm{~s}>0.12)$ but with lower word frequencies $t \mathrm{~s}>8.20, p \mathrm{~s}<0.001)$. HCD words have similar frequencies to the control condition $(t \mathrm{~s}<-1.60, p \mathrm{~s}>0.10)$ but with a higher $\mathrm{CD}$ value $(t \mathrm{~s}>10.60, p \mathrm{~s}<0.001)$. All were two-character compound nouns and matched in number of stokes $(t \mathrm{~s}<0.63, p \mathrm{~s}>0.39)$, radicals $(t \mathrm{~s}<0.30, p \mathrm{~s}>$ $0.53)$, orthographic neighborhood size $(t \mathrm{~s}<0.94, p \mathrm{~s}>$ 0.35 ), and semantic diversity ( $t \mathrm{~s}<0.87, \mathrm{ps}>0.39)$. Words immediately prior to and after the target word were matched in frequency, $\mathrm{CD}$, and strokes $(t \mathrm{~s}<1.49, \mathrm{ps}>$ $0.15)$ across conditions. Values for each condition are presented in the Appendix Table 8.

Norming studies were used to match plausibility and perceived difficulty across conditions ( $t \mathrm{~s}<1.28, p \mathrm{~s}>0.20)$. Cloze probability was $2.60 \%$ in Experiment $2 \mathrm{a}$ and $1.77 \%$ in Experiment $2 \mathrm{~b}$, with no significant differences across conditions $(t \mathrm{~s}<1.12, p \mathrm{~s}>0.27)$.

\section{Results}

We used the same exclusion criteria as in Experiment 1. For Experiment 2a, $7.83 \%$ of trials were excluded, and $6.77 \%$ for Experiment $2 \mathrm{~b}$. Tables 4 and 5 display means for each eye movement measure in each condition for Experiments $2 \mathrm{a}$ and $2 \mathrm{~b}$ respectively. As in Experiment 1, linear mixed-effects models and mixed logit models were used to implement planned comparisons. Results for Experiments $2 \mathrm{a}$ and $2 \mathrm{~b}$ are presented in Tables 6 and 7, respectively.

\section{Effects of word frequency (control group vs. LWF group)}

There were no reliable differences in first-pass measures and measures reflecting later processing in either experiment: For first pass measures in Experiment $2 \mathrm{a}$, all $t \mathrm{~s}<1$, $p \mathrm{~s}>0.30, \beta \mathrm{s}<10.10$ (for skipping rate, $z=-1.54, p=$ $0.123, \beta=-0.53$ ); for Experiment $2 \mathrm{~b}$, all $t \mathrm{~s}<1, p \mathrm{~s}>0.70$,

Table 5 Regression coefficients and test statistics from linear mixed-effects and logistic mixed-effects models for eye movement measures on the target in Experiment 2a

\begin{tabular}{|c|c|c|c|c|c|c|c|}
\hline & & FFD & GD & Skipping & Reg.in & Go-past & TTime \\
\hline \multirow[t]{4}{*}{ Control group vs. LWF group } & Est. $\beta$ & 4.02 & 10.09 & -0.53 & 0.06 & 13.14 & 17.31 \\
\hline & $t$-value & 0.87 & 0.87 & & 1.35 & 0.98 & 0.70 \\
\hline & $z$-value & & & -1.54 & & & \\
\hline & $p$-value & 0.391 & 0.39 & 0.123 & 0.188 & 0.335 & 0.491 \\
\hline \multirow[t]{4}{*}{ Control group vs. HCD group } & Est. $\beta$ & -15.44 & -29.79 & 0.46 & -0.04 & -68.28 & -70.79 \\
\hline & $t$-value & -2.49 & -2.53 & & -1.21 & -2.96 & -2.76 \\
\hline & $z$-value & & & 1.50 & & & \\
\hline & $p$-value & 0.018 & 0.016 & 0.134 & 0.237 & 0.006 & 0.009 \\
\hline
\end{tabular}


Table 6 Eye movement measures on target words in Experiment $2 \mathrm{~b}$

\begin{tabular}{llll}
\hline Measure & Control group & LWF group & HCD group \\
\hline FFD (ms) & $313(3.46)$ & $316(3.19)$ & $293(3.04)$ \\
GD (ms) & $386(6.35)$ & $384(6.52)$ & $339(4.05)$ \\
Skipping & $0.08(0.01)$ & $0.06(0.01)$ & $0.11(0.01)$ \\
Go-past (ms) & $545(9.42)$ & $551(8.21)$ & $452(7.82)$ \\
Reg. in & $0.15(0.01)$ & $0.20(0.02)$ & $0.12(0.01)$ \\
TTime (ms) & $522(9.39)$ & $538(10.14)$ & $425(6.47)$ \\
\hline
\end{tabular}

Note: All standard errors are provided in parentheses

$\beta \mathrm{s}<1.60$ (for skipping rate, $z=-1.57, p=0.117, \beta=-$ $0.63)$. For measures reflecting later processing in Experiment 2a, all $t \mathrm{~s}<1.36, p \mathrm{~s}>0.18, \beta \mathrm{s}<17.50$; for Experiment $2 \mathrm{~b}$, all $t \mathrm{~s}<1.27, p \mathrm{~s}>0.21, \beta \mathrm{s}<9.60$.

\section{Effects of contextual diversity (control group vs. HCD group)}

The data patterns were similar for Experiments 2a and 2b. For first-pass measures in Experiment 2a, HCD target words had shorter first-fixation durations $(\beta=-15.44)$ and gaze durations $(\beta=-29.79)$ than words with lower $\mathrm{CD}, t \mathrm{~s}>-2.53, p \mathrm{~s}<0.019$, with no effect of $\mathrm{CD}$ in skipping rate, $z=1.50, p=0.134, \beta=0.46$. In Experiment $2 \mathrm{~b}, \mathrm{HCD}$ target words had shorter firstfixation durations $(\beta=-19.85)$ and gaze durations $(\beta=$ -44.26) than words with lower CD, $t \mathrm{~s}>-3.48, p \mathrm{~s}<0.01$. There was no main effect of $\mathrm{CD}$ in skipping rate, $z=$ $1.28, p=0.199, \beta=0.41$.

For the later measures in Experiment 2a, go-past time $(\beta=-68.28)$ and total fixation time $(\beta=-70.79)$ were shorter for HCD words than Controls CD, $t \mathrm{~s}>-2.96, p \mathrm{~s}$ $<0.01$. The regression rate was numerically, but not significantly, lower for HCD words $(\beta=-0.04)$. For the later measures in Experiment 2b, go-past time $(\beta=-90.34)$ and total fixation time $(\beta=-95.03)$ were shorter for HCD words, $t \mathrm{~s}>-4.27, p \mathrm{~s}<0.01$. The regression rate was again, numerically, but not significantly different $(\beta=-$ 0.03 )

We note that the first-fixation durations varied across the three experiments. Experiment 1 and Experiment $2 b$ have relatively long fixation durations compared to Experiment 2a, and some other experiments in the literature (e.g., Cui, Yan, Bai, Hyönä, Wang, \& Liversedge, 2013; Yan, Tian, Bai, \& Rayner, 2006). As noted earlier, they are nonetheless within the range of commonly observed fixation durations ( $\mathrm{Li}$ et al., 2014). In contrast, the first fixations in Experiment 2a are on the shorter end of the distribution. It is difficult to compare across experiments because fixation durations can be variable (McBride-Chang \& Chen, 2003). Moreover, the words selected in these experiments are a tightly constrained set, which complicates comparisons with other studies in the literature. That said, in Experiments 1 and 2b, which had longer first fixations, the overall CDs were similar between the two experiments, and they were considerably lower than in Experiment 2a, which had the shorter fixation durations. This is the expected pattern.

Four of the six measures showed small differences that would be consistent with a frequency effect. When combined with Plummer et al., 19 of 25 measures showed small differences in the same direction (P (19) $=0.005$ by Binomial test, though that $p$-value is almost certainly inflated because the binomial test assumes that the measures are not correlated, which is almost certainly not the case. Crucially, however, whereas log frequency differences are larger for Experiment $2 \mathrm{~b}$ compared to Experiment 2a, for most measures the differences between LWF group and Control group are slightly smaller (Please see Fig. 1). This is inconsistent with a frequency-based explanation.

Table 7 Regression coefficients and test statistics from linear mixed-effects and logistic mixed-effects models for eye movement measures on the target in Experiment $2 \mathrm{~b}$

\begin{tabular}{|c|c|c|c|c|c|c|c|}
\hline & & FFD & GD & Skipping & Reg.in & Go-past & TTime \\
\hline \multirow[t]{4}{*}{ Control group vs. LWF group } & Est. $\beta$ & 1.56 & -3.34 & -0.63 & 0.05 & 8.01 & 9.54 \\
\hline & $t$-value & 0.35 & -0.30 & & 1.26 & 0.61 & 0.40 \\
\hline & $z$-value & & & -1.57 & & & \\
\hline & $p$-value & 0.729 & 0.766 & 0.117 & 0.215 & 0.544 & 0.690 \\
\hline \multirow[t]{4}{*}{ Control group vs. HCD group } & Est. $\beta$ & -19.85 & -44.26 & 0.41 & -0.03 & -90.34 & -95.03 \\
\hline & $t$-value & -3.17 & -3.47 & & -1.02 & -4.26 & -3.74 \\
\hline & $z$-value & & & 1.28 & & & \\
\hline & $p$-value & 0.003 & 0.001 & 0.199 & 0.315 & 0.0002 & 0.001 \\
\hline
\end{tabular}




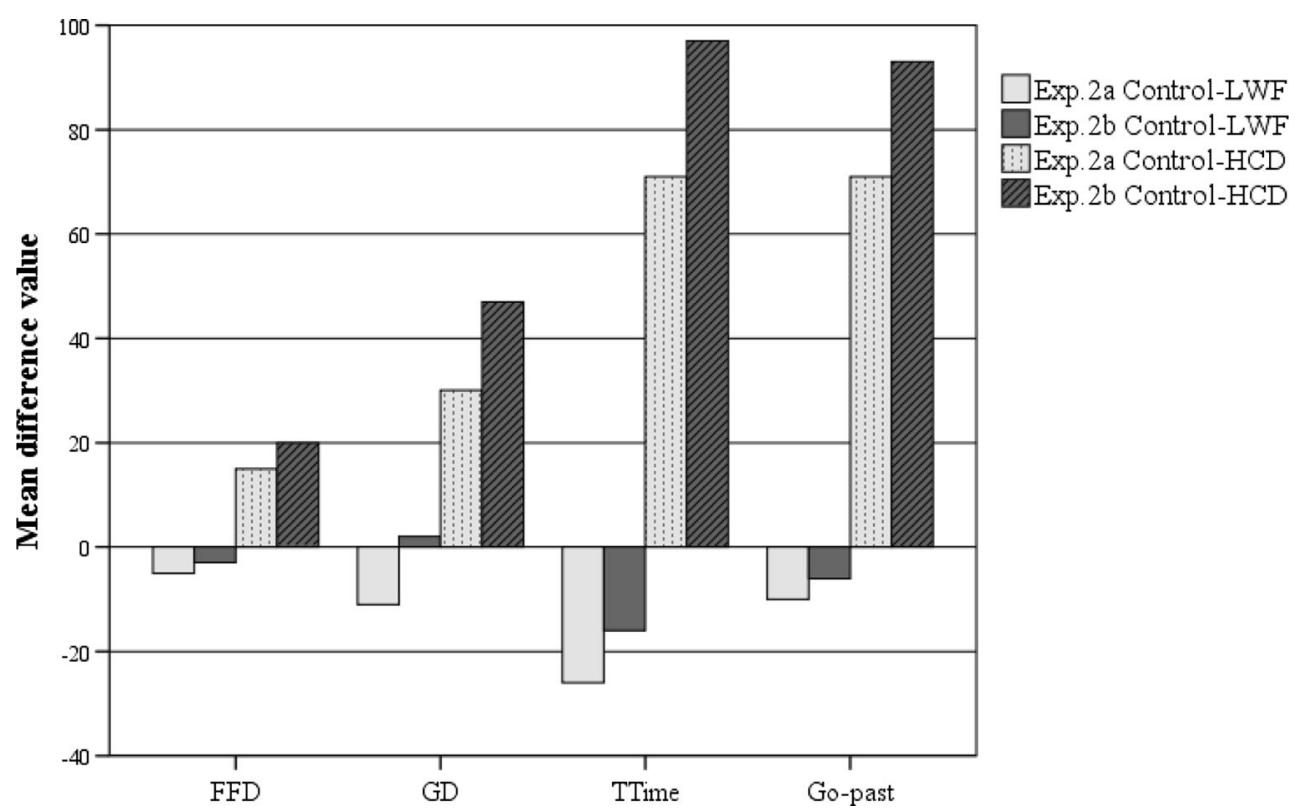

Fig. 1 Differences in values in the smaller (Exp. 2a) and larger frequency range (Exp. 2b)

\section{General discussion}

The current studies make three contributions. First, we replicate Plummer et al.'s finding that frequency does not affect fixation patterns when $\mathrm{CD}$ is controlled, using a design in which sentence frames are matched across conditions. Second, we provide novel evidence that the absence of frequency effects is not the result of using a restricted range of frequencies. Third, we extend the evidence for $\mathrm{CD}$ effects in silent reading to Mandarin.

As Plummer et al. (2014) note, the absence of a frequency effect is only compatible with models of visual word recognition in which frequency of occurrence is the relevant dimension if we make the implausible assumption that $\mathrm{CD}$ measures are better estimates of frequency of occurrence than frequency per se.

A more likely explanation is that $\mathrm{CD}$ provides a better measure of the prior that a reader would have for encountering a particular word, a notion that is compatible with Smith and Levy's (2013) conclusion that predictability is the primary determinant of word-level reading time. When $\mathrm{CD}$ is matched, the differences in token frequency arise because the higher frequency words occur more often within specific contexts. That is, once one sees that word, it is more likely to re-occur. In the absence of reliable information that one is in such a context, the priors would be the same. This maps onto the situation common in most studies of word recognition, where either there is little or no context (words in isolation) or words are presented in sentences constructed to test psycholinguistic hypotheses.

The more far-reaching implication is that instantiating a context that increases the likelihood of encountering a word or class of words, e.g., a report about a baseball game, would be an even more powerful predictor of reading time than $\mathrm{CD}$, especially for words with lower CD measures in which the contexts (e.g., type of texts) a word occurs in are either thematically related or share genres. For example, subcategorization frequency and sense-based frequencies of argument structures (e.g., Hare, McRae, \& Elman, 2003) are context and genre dependent. Examining the interaction between $\mathrm{CD}$ and context-specific effects might then shed light on the organization of semantic memory and the lexical processing in natural contexts. For example, "frequency" effects for words and structures are likely to differ across different genres, including texts written for readers of different ages or readers with different levels of expertise.

Chinese might prove particularly useful for examining the issues because the sense of a word and the sense of a character bear a quasi-systematic relationship. In Chen et al. (submitted) we demonstrate $\mathrm{CD}$ effects (with no residual frequency effects) for the first character of a two-character word, with those effects being smaller in magnitude than the word-level $\mathrm{CD}$ effects reported in this paper. Comparisons of alphabetic languages with languages like Chinese might also help tease apart word-level context effects from lower-level orthographic/phonotactic effects.

Acknowledgments This paper benefited from Simon Liversedge's cogent review and comments from Anne Pier Salverda. This work was supported by grants from the Major State Basic Research Development Program of China (973 Program, 2014CB340502), the Major Program of the Social Science Foundation of China (10\&ZD126, 13\&ZD189), the Natural Science Foundation of China (31100814), the China Postdoctoral Science Foundation (2014M560433), the Postdoctoral Science Foundation of Jiangsu Province (1401061B), and the Social Science Foundation of China (14BSH077). Michael K. Tanenhaus was supported by NIH grants HD 27206 and HD 073890. 


\section{Appendix}

Table 8 Characteristics of the target words in Experiment 1 and Experiment 2

\begin{tabular}{|c|c|c|c|}
\hline Measure & Control group & LWF group & HCD group \\
\hline \multicolumn{4}{|c|}{ Characteristics of the target words in each group for Experiment 1} \\
\hline Mean word frequency (log) & $2.26(0.05)$ & $1.44(0.05)$ & $2.30(0.02)$ \\
\hline Word frequency range (log) & $2.00-3.04$ & $0.70-1.68$ & $2.14-2.47$ \\
\hline Mean contextual diversity $(\log )$ & $1.53(0.05)$ & $1.43(0.05)$ & $2.22(0.02)$ \\
\hline Contextual diversity range (log) & $0.70-1.91$ & $0.70-1.68$ & $2.11-2.34$ \\
\hline Number of strokes & $16.59(1.02)$ & $14.89(0.77)$ & $16.82(0.73)$ \\
\hline Number of radicals & $4.30(0.26)$ & $4.26(0.24)$ & $4.74(0.25)$ \\
\hline Orthographic neighborhood size & $101.78(11.86)$ & $106.22(11.08)$ & $113.67(14.69)$ \\
\hline Semantic diversity & $1.59(0.15)$ & $1.63(0.15)$ & $1.82(0.25)$ \\
\hline \multicolumn{4}{|c|}{ Characteristics of the target words in Experiment 2a } \\
\hline Mean word frequency $(\log )$ & $2.77(0.05)$ & $2.36(0.01)$ & $2.88(0.05)$ \\
\hline Word frequency range (log) & $2.60-3.34$ & $2.29-2.47$ & $2.71-3.55$ \\
\hline Mean contextual diversity $(\log )$ & $2.13(0.03)$ & $2.02(0.06)$ & $2.77(0.05)$ \\
\hline Contextual diversity range (log) & $1.91-2.39$ & $1.51-2.32$ & $2.63-3.36$ \\
\hline Number of strokes & $16.19(1.22)$ & $15.56(0.85)$ & $14.94(0.77)$ \\
\hline Number of radicals & $4.19(0.36)$ & $4.25(0.25)$ & $4.44(0.27)$ \\
\hline Orthographic neighborhood size & $304.19(52.22)$ & $289.06(45.27)$ & $281.78(4.23)$ \\
\hline Semantic diversity & $2.38(0.46)$ & $2.31(0.46)$ & $2.75(0.40)$ \\
\hline Pre-target word frequency & $4.61(0.29)$ & $4.60(0.18)$ & $4.65(0.24)$ \\
\hline Post-target word frequency & $4.20(0.30)$ & $4.17(0.24)$ & $4.13(0.33)$ \\
\hline Pre-target word CD & $3.58(0.07)$ & $3.70(0.03)$ & $3.64(0.07)$ \\
\hline Post-target word CD & $3.42(0.09)$ & $3.45(0.10)$ & $3.38(0.12)$ \\
\hline Pre-target word strokes & $13.25(1.30)$ & $13.25(1.31)$ & $12.56(1.30)$ \\
\hline Post-target word strokes & $13.13(1.36)$ & $13.94(1.44)$ & $13.38(1.26)$ \\
\hline \multicolumn{4}{|c|}{ Characteristics of the target words in Experiment $2 b$} \\
\hline Mean word frequency $(\log )$ & $2.36(0.05)$ & $1.30(0.10)$ & $2.47(0.05)$ \\
\hline Word frequency range (log) & $2.11-2.80$ & $0.15-1.61$ & $2.18-2.81$ \\
\hline Mean contextual diversity $(\log )$ & $1.48(0.07)$ & $1.34(0.08)$ & $2.36(0.05)$ \\
\hline Contextual diversity range (log) & $0.70-1.87$ & $0.70-1.61$ & $2.12-2.72$ \\
\hline Number of strokes & $16.00(1.89)$ & $14.69(0.99)$ & $16.31(0.95)$ \\
\hline Number of radicals & $4.06(0.36)$ & $3.94(0.21)$ & $4.00(0.24)$ \\
\hline Orthographic neighborhood size & $365.00(134.89)$ & $286.81(67.64)$ & $231.28(49.19)$ \\
\hline Semantic diversity & $2.50(0.62)$ & $1.94(0.21)$ & $2.69(0.29)$ \\
\hline Pre-target word frequency & $4.58(0.32)$ & $4.44(0.30)$ & $4.36(0.28)$ \\
\hline Post-target word frequency & $3.98(0.30)$ & $3.95(0.32)$ & $4.05(0.33)$ \\
\hline Pre-target word CD & $3.49(0.12)$ & $3.49(0.11)$ & $3.49(0.08)$ \\
\hline Post-target word CD & $3.31(0.12)$ & $3.28(0.16)$ & $3.29(0.15)$ \\
\hline Pre-target word strokes & $13.88(1.55)$ & $13.06(1.29)$ & $13.31(1.14)$ \\
\hline Post-target word strokes & $12.94(1.53)$ & $12.25(1.16)$ & $13.31(1.12)$ \\
\hline
\end{tabular}

Note: All standard errors are provided in parentheses 


\section{References}

Adelman, J. S., Brown, G. D., \& Quesada, J. F. (2006). Contextual diversity, not word frequency, determines word-naming and lexical decision times. Psychological Science, 17, 814-823.

Adelman, J. S., \& Brown, G. D. (2008). Modeling lexical decision: The form of frequency and diversity effects. Psychological Review, 115, 214-229.

Barr, D. J., Levy, R., Scheepers, C., \& Tily, H. J. (2013). Random effects structure for confirmatory hypothesis testing: Keep it maximal. Journal of Memory and Language, 68, 255-278.

Bates, D., Maechler, M., \& Bolker, B. (2012). lme4: Linear mixed-effects models using S4 classes (R package version 0.999999-0). Retrieved from http://CRAN.R-project.org/package=lme4.

Cai, Q., \& Brysbaert, M. (2010). SUBTLEX-CH: Chinese word and character frequencies based on film subtitles. PLOS ONE, 5, e10729.

Cui, L., Yan, G. L., Bai, X. J., Hyönä, J., Wang, S. P., \& Liversedge, S. (2013). Processing of compound-word characters in reading Chinese: An eye-movement-contingent display change study. The Quarterly Journal of Experimental Psychology, 66, 527-547.

Chen, Q. R., \& Huang, Y. (2012). Processing Coordinate Structures in Chinese: Evidence from Eye Movements. PLoS ONE, 7, e35517.

Hare, M., McRae, K., \& Elman, J. L. (2003). Sense and structure: Meaning as a determinant of verb subcategorization preferences. Journal of Memory and Language, 48, 281-303.

Hills, T. T., Maouene, J., Riordan, B., \& Smith, L. B. (2010). The associative structure of language: Contextual diversity in early word learning. Journal of Memory and Language, 63, 259-273.

Hoffman, P., Lambon Ralph, M. A., \& Rogers, T. T. (2013). Semantic diversity: A measure of semantic ambiguity based on variability in the contextual usage of words. Behavior Research Methods, 45, 718-730.

Hoffman, P., Rogers, T. T., \& Ralph, M. A. L. (2011). Semantic diversity accounts for the "missing" word frequency effect in stroke aphasia: Insights using a novel method to quantify contextual variability in meaning. Journal of Cognitive Neuroscience, 23, 2432-2446.

Inhoff, A. W., \& Rayner, K. (1986). Parafoveal word processing during eye fixations in reading: Effects of word frequency. Perception and Psychophysics, 40, 431-439.

Jaeger, T. F. (2008). Categorical data analysis: Away from ANOVAs (transformation or not) and towards logit mixed models. Journal of Memory and Language, 59, 434-446.

Johns, B. T., Gruenenfelder, T. M., Pisoni, D. B., \& Jones, M. N. (2012). Effects of word frequency, contextual diversity, and semantic distinctiveness on spoken word recognition. The Journal of the Acoustical Society of America, 132, EL74-EL80.

Jones, M. N., Johns, B. T., \& Recchia, G. (2012). The role of semantic diversity in lexical organization. Canadian Journal of Experimental Psychology, 66, 121-132.
Kuznetsova, A., Christensen, R. H. B., \& Brockhoff, P. B. (2014). LmerTest: Tests for random and fixed effects for linear mixed effect models (lmer objects of lme4 package). R Package Version, 2, 0-6.

Li, X., Bicknell, K., Liu, P. P., Wei, W., \& Rayner, K. (2014). Reading is fundamentally similar across disparate writing systems: A systematic characterization of how words and characters influences eye movements in Chinese reading. Journal of Experimental Psychology: General, 143, 895-913.

Li, X., \& Pollatsek, A. (2011). Word knowledge influences character perception. Psychonomic Bulletin \& Review, 18, 833-839.

Liversedge, S. P., Zang, C. L., Zhang, M. M., Bai, X. J., Yan, G. L., \& Drieghe, D. (2014). The effects of visual complexity and word frequency on eye movements during Chinese reading. Visual Cognition, 22, 441-457.

McBride-Chang, C., \& Chen, H.-C. (2003). Reading Development in Chinese Children. London: Praeger.

Perea, M., Soares, A. P., \& Comesaña, M. (2013). Contextual diversity is a main determinant of word identification times in young readers. Journal of Experimental Child Psychology, 116, 37-44.

Plummer, P., Perea, M., \& Rayner, K. (2014). The influence of contextual diversity on eye movements in reading. Journal of Experimental Psychology: Learning, Memory, and Cognition, 40, 275-283.

R Development Core Team (2014). R: A language and environment for statistical computing. R Foundation fro Statistical Computing, Vienna, Austria. ISBN 3-900051-07-0, URL http://www.R-project. org

Rayner, K., \& Duffy, S. A. (1986). Lexical complexity and fixation times in reading: Effects of word frequency, verb complexity, and lexical ambiguity. Memory \& Cognition, 14, 191-201.

Rayner, K. (1998). Eye movements in reading and information processing: 20 years of research. Psychological Bulletin, 124, 372-422.

Rayner, K. (2009). Eye movements and attention in reading, scene perception, and visual search. The Quarterly Journal of Experimental Psychology, 62, 1457-1506.

Smith, N. J., \& Levy, R. (2013). The effect of word predictability on reading time. Cognition, 128, 302-319.

Steyvers, M., \& Malmberg, K. J. (2003). The effect of normative context variability on recognition memory. Journal of Experimental Psychology: Learning, Memory, and Cognition, 29, 760-766.

Williams, R. S., \& Morris, R. K. (2004). Eye movements, word familiarity, and vocabulary acquisition. European Journal of Cognitive Psychology, 16, 312-339.

Yan, G., Tian, H., Bai, X., \& Rayner, K. (2006). The effect of word and character frequency on the eye movements of Chinese readers. British Journal of Psychology, 97(2), 259-268.

Yap, M. J., Tan, S. E., Pexman, P. M., \& Hargreaves, I. S. (2011). Is more always better? Effects of semantic richness on lexical decision, speeded pronunciation, and semantic classification. Psychonomic Bulletin \& Review, 18, 742-750. 